SAND77-0715

Unlimited Release

RECEIVED BY TIC AUG 31 1977

\title{
An Overview of the SECOM II Communications System
}

Wayne D. Olson

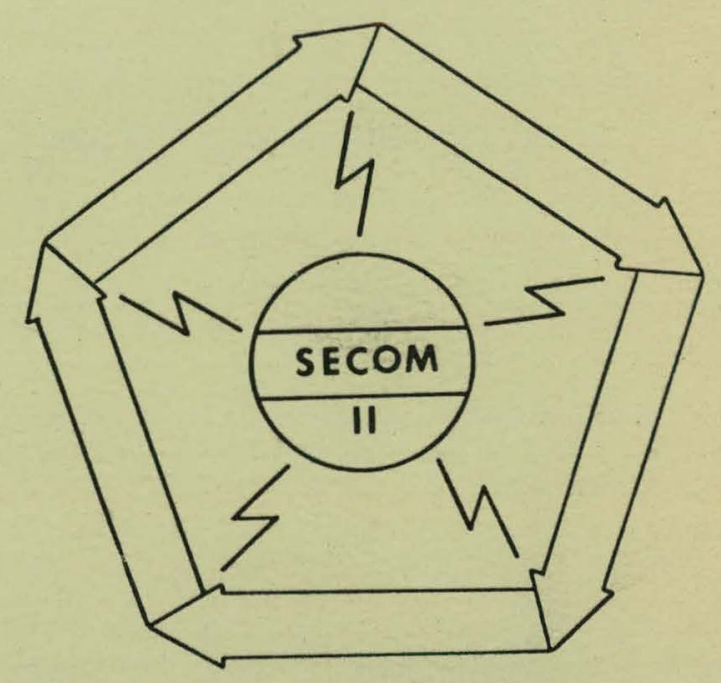

Prepared by Sandia Lahoratories, Albuquerque New Mexico 87115

and Livermore, Califorma 94550 for the United States Emaray Researchi

and Development Administration under Contract AT (29-1) 789

Printed April 1977

\section{[1] Sandia Laboratories}




\section{DISCLAIMER}

This report was prepared as an account of work sponsored by an agency of the United States Government. Neither the United States Government nor any agency Thereof, nor any of their employees, makes any warranty, express or implied, or assumes any legal liability or responsibility for the accuracy, completeness, or usefulness of any information, apparatus, product, or process disclosed, or represents that its use would not infringe privately owned rights. Reference herein to any specific commercial product, process, or service by trade name, trademark, manufacturer, or otherwise does not necessarily constitute or imply its endorsement, recommendation, or favoring by the United States Government or any agency thereof. The views and opinions of authors expressed herein do not necessarily state or reflect those of the United States Government or any agency thereof. 


\section{DISCLAIMER}

Portions of this document may be illegible in electronic image products. Images are produced from the best available original document. 
Issued by Sandia Laboratories, operated for the United States Energy Research \& Development Administration by Sandia Corporation.

\section{NOTICE}

This report was prepared as an account of work sponsored by the United States Government. Neither the United States nor the United States Energy Research \& Development Administration, nor any of their employees, nor any of their contractors, subcontractors, or their employees, makes any warranty, express or implied, or assumes any legal liability or responsibility for the accuracy, completeness or usefulness of any information, apparatus, product or process disclosed, or represents that its use would not infringe privately owned rights.

Printed in the United States of America Available from

National Technical Information Service U.S. Department of Commerce 5285 Port Royal Road Springfield, VA 22161

Price: Per Copy $\$ 4.00 \quad 4.50$ Microfiche $\$ \overline{2.25} \quad 3.00$ 
An Overview of the

SECOM II Communications system

Prepared by

wayne D. Olson

In Collaboration with Members of

Division 1715

Sandia Laboratories

Albuquerque, NM

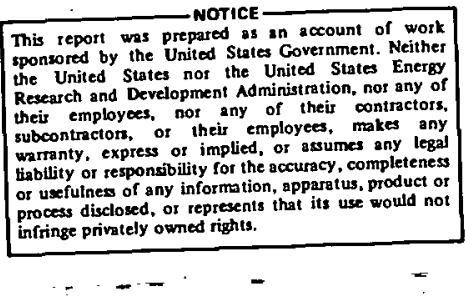

Introduction

In June, 1974, in response to a request from the Albuquerque Operations office (ALO) and the agreements reached at the June 4-5, 1974 planning meeting for the Single Manager Transportation System held at ERDA Headquarters, Sandia Laboratories began the task of designing a two-way digital communications system to provide reliable communications between a central controller and the expanding fleet of vehicles carrying nuclear weapons and special nuclear material anywhere in the country. An initial operating capability was provided in April 1976, and the syste $n$ became fully operational in March 1977.

\section{Preliminary System Definition}

The requirements for the system are shown in Figure 1. The requirement for coverage over the 48 contiguous states limited the approaches that could be followed. Radiotelephone was eliminated immediately due to the lack of coverage in many areas of the country. Meteor burst communications could not be considered since no significant delays could be accepted in case a vehicle is involved in an emergency. A satellite system appeared attractive but was eliminated because of the long development time and very high cost. Thus, the only viable 
approach that remained was an HF (High Frequency) radio network. Fortunately, ALO had previously developed and implemented a nationwide HF network utilizing voice transmissions. Their security Communications (SECOM) system utilized five relay stations connected to the central control station by leased telephone lines as shown in Figure 2 . Conversion of this system from voice to two-way digital appeared to provide the most logical approach to providing the increased capacity needed to handle the expanded fleet of vehicles required by the Single Manager Transportation System within the time available.

Once the decision to proceed with the HF network was made, a study of the SECOM voice system was made to determine areas where a digital system could improve the reliability of two-way communications. The most significant problem in voice operations appeared to be the need to predict ionospheric conditions that affected propagation of HF signals. As the conditions changed, it was necessary to change to a different channel to maintain communications. To overcome the need to predict propagation conditions, it was decided that the digital message would not be transmitted on the optimum channel only. Instead, it would be sent on several different channels across the band sequentially. In this way, at least one channel would always be optimum. After reviewing ALO's frequency usage data, SECOM channels $1,3,5$ and 8 were chosen for the digital system. While this approach solved the problem for the vehicle operator, it became immediately obvious that it was unnecessary for the central control station to transmit responses on all four channels. By simply observing the number of incoming messages received on each channel, the "best channel" for response could be easily determined. In a similar manner, the "best relay station" and the "best antenna" could be determined. Thus, the approach followed was to have the vehicle transmit on the four channels sequentially and to have the control center response sent via the station, antenna, and channel determined to be "best" by observation of incoming message counts. 
To provide the vehicle operator with assurance that his message had been received at the central control station, it was decided that an "acknowledge" message should be transmitted in response to each incoming vehicle message. In the event that an "acknowledge" was not received by the vehicle, the operator could initiate another transmission attempt. Further thoughts along this line soon led to the conclusion that it would be more desirable to design the vehicle equipment to automatically reinitiate the message transmission whenever the "acknowledge" was not received within a reasonable time. Based on estimated times for the normal transmission sequence, 30 seconds was chosen for the minimum time interval before another transmission should be initiated. Recognizing that one probable reason for an unsuccessful communication attempt would be simultaneous transmissions by two vehicles, the interval between transmissions was made variable from 30 to 40 seconds to prevent repeated overlapping of messages. The maximum number of transmission attempts for any message was set to five in the belief that the vehicle operator should resort to alternate procedures if he has not been successful after five attempts.

The basic features of the modified system, subsequently named SECOM II, were thus defined as shown in Figure 3. The configuration of the SECOM II system is shown in Figure 4.

\section{Vehicle Eguipment}

The equipment designed for vehicle installations consists of a vehicle control box (VCB), a vehicle interface box (VIB), and a transceiver and antenna coupler (Figure 5). The transceiver is an all solid-state design which has four fixed-tuned receiver channels and a selectable, four-frequency, 100 watt transmitter. The transceiver and coupler both utilize relay switching for 
fast, reliable channel selection. The VIB contajns all of the ejectronics and controls that do not reguire access during a trip.

The VCB is the control unit for the vehicle system and provides the man/machine interface. A front vjew of the VCB is shown in Figure 6. In addition to the normal. control functions (ON/OFF, DIGITAL/VOICE SELECT, etc.), the unit has a calculator-type keyboard for entering digits into the system. l'o initiate a message, the operator must enter nine digits via the keyboard. As each key is depressed, the digit is disp] ayed in the numeric display above the keyboard. An operator will first enter four digits to represent vehicle location and they will appear in displays 1-4. The next three digits (5-7) are authenticators. The last two digits (8-9), are a 10-code type message using a specially defined vocabulary. When the nine digits have been entered and visually verified by the operator, depressing the transmit switch (XMIT) begins the automatic sequence. The system will. format a 1.00-bit (25 digit) message incorporating the nine operator-inserted digits, the vehicle icentification digits, a message type digit, three auxiliary digits (for future growth), a preamble, and an error-detecting cyclic redundancy code (CRC). The format of the message is shown in Figure 7 . The message $j$ s transmitted in bj-phase FSK coding at 300 bits per second utjlizing 3.300 and $2100 \mathrm{~Hz}$ tones. The l00-bit message is transmitted twice on each of the four channeis in the seguence shown in Figure 8 . In approximately 18 seconds, the "acknowledge". message will be received by the vehicle and a "00" message (defined to mean acknowledge) will. be displayed in pnsitinns 10 and 11 of the VCB. In addition, the REC (received) light will illuminate; an alerting tone will sound, and the vehicle sequence will. stiop. However, if the "acknowledge". is not recejved within 30 to 40 seconds, the system will automatically initiate another transmission sequence. In the rare case where fjue attempts have been made without receiving 
an "acknowledge", the sequence will stop, the N/REC (not received) light will illuminate, and the alerting tone will sound to inform the operator that he must revert to an alternate communication procedure.

The system also contains an "alert" timer to inform the operator when it is time for $h$ is scheduled report. The interval is settable in 30 minute steps by means of the TME thumbwheel switch. Once an interval has been selected, the system will sound an alert tone and illuminate the ALERT light five minutes before the desired interval from his last transmission has elapsed: The operator then has ample time to complete his transmission before his scheduled time elapses.

Should an emergency occur, the operator can initiate a pre-formatted emergency message by simply lifting the springloaded cover in the upper left corner of the VCB and depressing the $\mathrm{E}$ (emergency) switch. Additional emergency switches can be Jocated at other positions within the vehicle to allow other crew members to initiate an emergency transmission.

SECOM II equipment has been installed in a variety of ERDA vehicles. Two typical examples, a carryall and a semi-tractor, are shown in Figures 9 through 12. After many thousands of miles over the road, the equipment has been proven to be very rugged and reliable.

\section{Rèlay Stations}

The original SECOM relay stations have been modified to the SECOM II configuration. Each station consists of an equipment building or trailer and four or five antennas oriented for optimum coverage. A typical station is shown pictorially in Figure 13. The functions performed at each of the unmanned 
stations are shown in Figure 14 and a block diagram of the jnformation flow is shown in Figure 15. Attached to each antenna is a fixed-tuned receiver for each of the four frequencies used in the system. Digita] messages received by these receivers and decoded by the tone receivers are fed to a National Semiconductor IMP-16 microcomputer. Since a single vehicle message can be received on more than one antenna and over more than one channel, the IMP is programmed to accept these multiple messages and perform a bit-by-bit majority logic check to arrive at a single message. A cyclic redundancy code check is then made to assure that no messages containing transmission errors are allowed to enter the system. The IMP then attaches received message count data to the vehicle message, generates a new error detecting code, and transmits the combined message over a leased telephone line to the SECOM Control Center (SCC) at ERDA/ALO.

When the SCC wishes to send a digital message to a vehicle, it is transmitted over the same leased telephone line to the IMP. The IMP passes the control portion of the message to the site interface box (SIB) which selects the proper 1000 watt transmitter, tunes it to the correct channel, selects the desired antenna, and keys the transmitter. The IMP then supplies the digital message to modulate the transmitter.

A secondary leased telephone line is brought to each station for backup digital or voice operation. If the primary line goes down, the secondary line will be switched. in automatically to provide continued digital operation. When voice operation is desired, a control. message is sent by the SCC over the primary ine to the IMP. As soon as the station is properly configured, the secondary line is enabled to allow the SCC operator to send and receive voice from that station.

A test set is provided at each relay station to provide the sCC operator with a capability of verifying proper station operation. The test set is essentially a vehicle package with 
its output attenuated $20 \mathrm{db}$ and its ID set to a number assigned permanently to that station. When the test set is interrogated by having the station transmit a request to that ID, the set responds with a standard vehicle transmission sequence. Since the test set is located at the antenna site, the messages are received by the antennas without any propagation uncertainty. Thus, every message sent should be received by every antenna on every frequency. At a four antenna station that is functioning properJy, 32 messages should be received during a test $(2$ messages/channe], 4 channels/antenna, 4 antennas).

\section{Central Control station}

The SCC is the nerve center of the SECOM II system. From here, two operators receive all. incoming messages and control the entire system. A view of one operator station is shown in Figure 16. To assist the operators, a dual ECLIPSE $B$ computer processes a]J digital data, performing the functions listed in Figure 1.7. In addition to merging the messages from up to five relay stations, performing majority logic and CRC code checks, the Eclipse analyzes incoming message count data and determines the best station, antenna, and channel for response messages. An "acknowledge" message is then generated automatically and sent to the appropriate station for transmission to the vehicle. (The format for an SCC-injtiated message is shown in Figure 1.8.) The incoming message is then displayed on the cathode-ray-tube (CRT) and printed on the line printer. At this point, the operator takes over, interpreting the message and determing what action is required, if any. The operator has the capabijity of initiating a message to any vehicle in the fleet, interrogating any vehicle, conducting relay station self-tests,

\section{(B) Registered trademark of Data General Corporation}


configuring a relay station for voice operation, and monitoring relay station equipment status. A typical operator CRT display is shown in the upper portion of Figure 19. The information displayed consists of the time of the last message received from each vehicle, the last message contents, and the last message sent to that vehicle. In the event that a vehicle sends an emergency message, a special display is brought up on the lower portion of the screen as shown in the lower view of Figure 19. The emergency display shows the last message received for all vehicles in the convoy from which the emergency was received.

A block diagram of the equipment included in the SCC is shown in Figure 20. To achieve the reliability required, all critical elements in the system are redundant. In addition, if the SCC becomes uninhabitable (due to a fire, etc.), a capability has been provided to operate the system from an alternate control. center (ACC) at the New Mexico (Albuquerque) relay station or the Missouri (Kansas City) relay station. The configuration of the leased telephone line network for normal and for ACC operation is shown in Figure 21 .

\section{Summary}

The conversion of the SECOM system to the SECOM II configuration has been completed and all communications between the central control station and vehicles carrying nuclear weapons and special nuclear materials are being handled by the SECOM II system. A summary of the system characteristics and the improvements achieved over the all-voice system is shown in Figure 22. Through the combined efforts of ALO and Sandia personnel, the transition from SECOM to SECOM II was achieved with a minimum disruption to the operation of the ERDA transportation system. 


\section{SYSTEM REQUIREMENTS}

COVERAGE OVER 48 CONTIGUOUS STATES

CAPACITY TO HANDLE MANY SIMULTANEOUS SHIPMENTS

RELIABLE TWO-WAY COMMUNICATIONS

OPERATION INDEPENDENT OF VEHICLE PERSONNEL

MINIMUM COST, INCONSPICUOUS VEHICLE INSTALLATION

CONTROL CENTER. TO PROVIDE:

POSITION DISPLAY

OPERATOR INTERFACE FOR VEHICLE COMMUNICATIONS

(COMMANDS/ROUTINE/EMERGENCY)

DATA STORAGE

FIGURE 1 


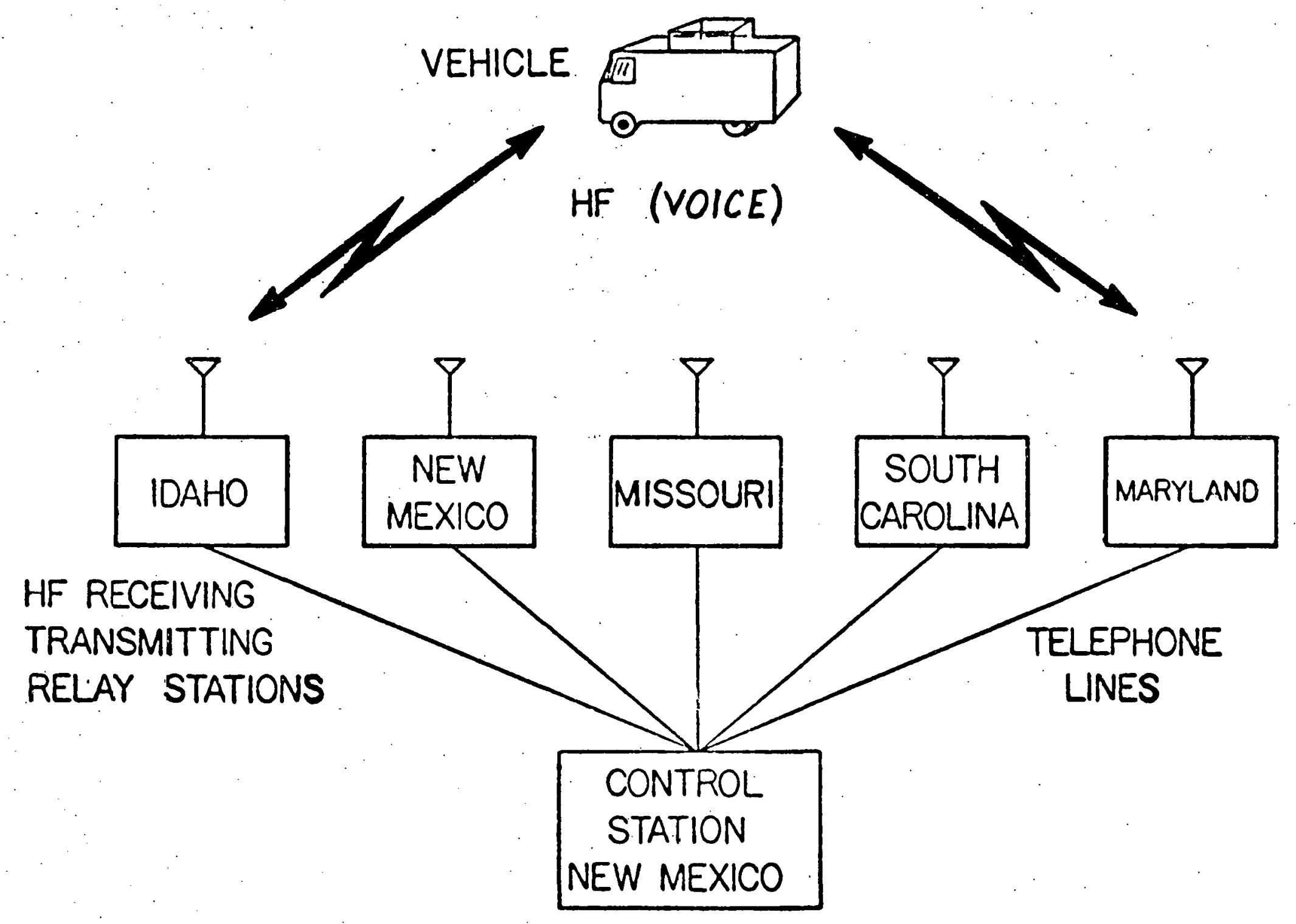

SECOM I SYSTEM 


\section{SECOM II FEATURES}

HF NETWORK OF FIVE UNMANNED RELAY STATIONS

RELAY STATIONS LINKED TO CONTROL. STATION VIA LEASED TELEPHONE LINES

TWO-WAY DIGITAL MESSAGES WITH EMERGENCY VOICE OPTION

VEHICLE MESSSAGES AUTOMATICALLY SENT OVER FOUR HF FREQUENCIES

CONTROL CENTER RESPONSE MESSAGES SENT OVER "BEST" RELAY STATION, ANTENNA, AND CHANNEL ONLY

EACH VEHIC ME MESSAGE "ACKNOWLEDGED" BY CONTROL CENTER

AUTOMATIC PETRANSMISSION OF VEHICLE MESSAGE IF NOT "ACKNOWLEDGED" (UP. TO 5 ATTEMPTS) 


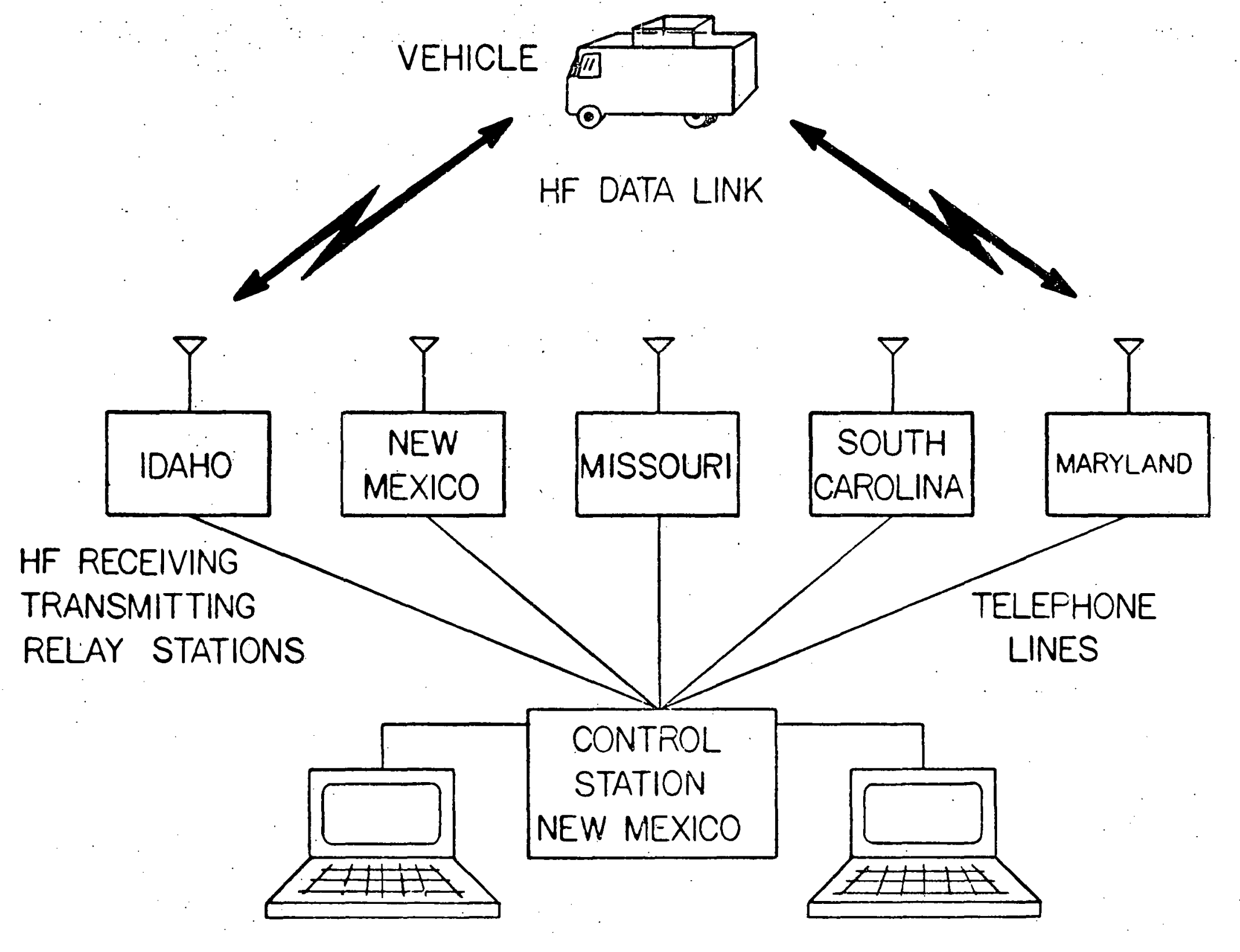

SECOM II SYSTEM

FIGURE 4 


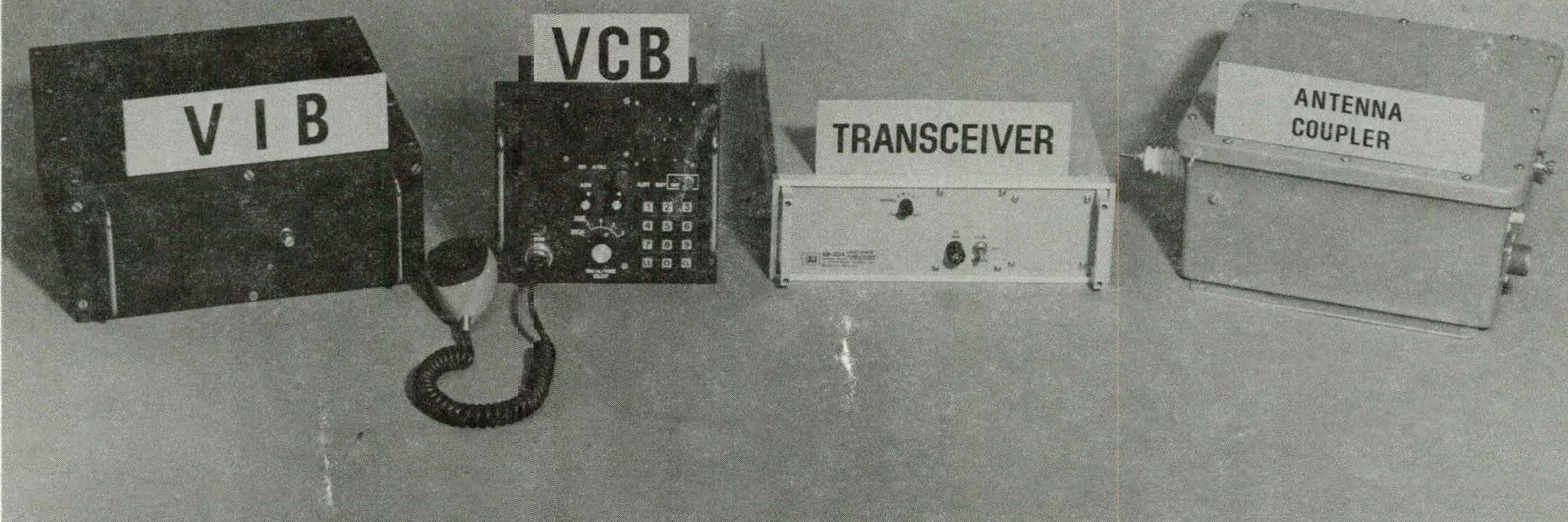




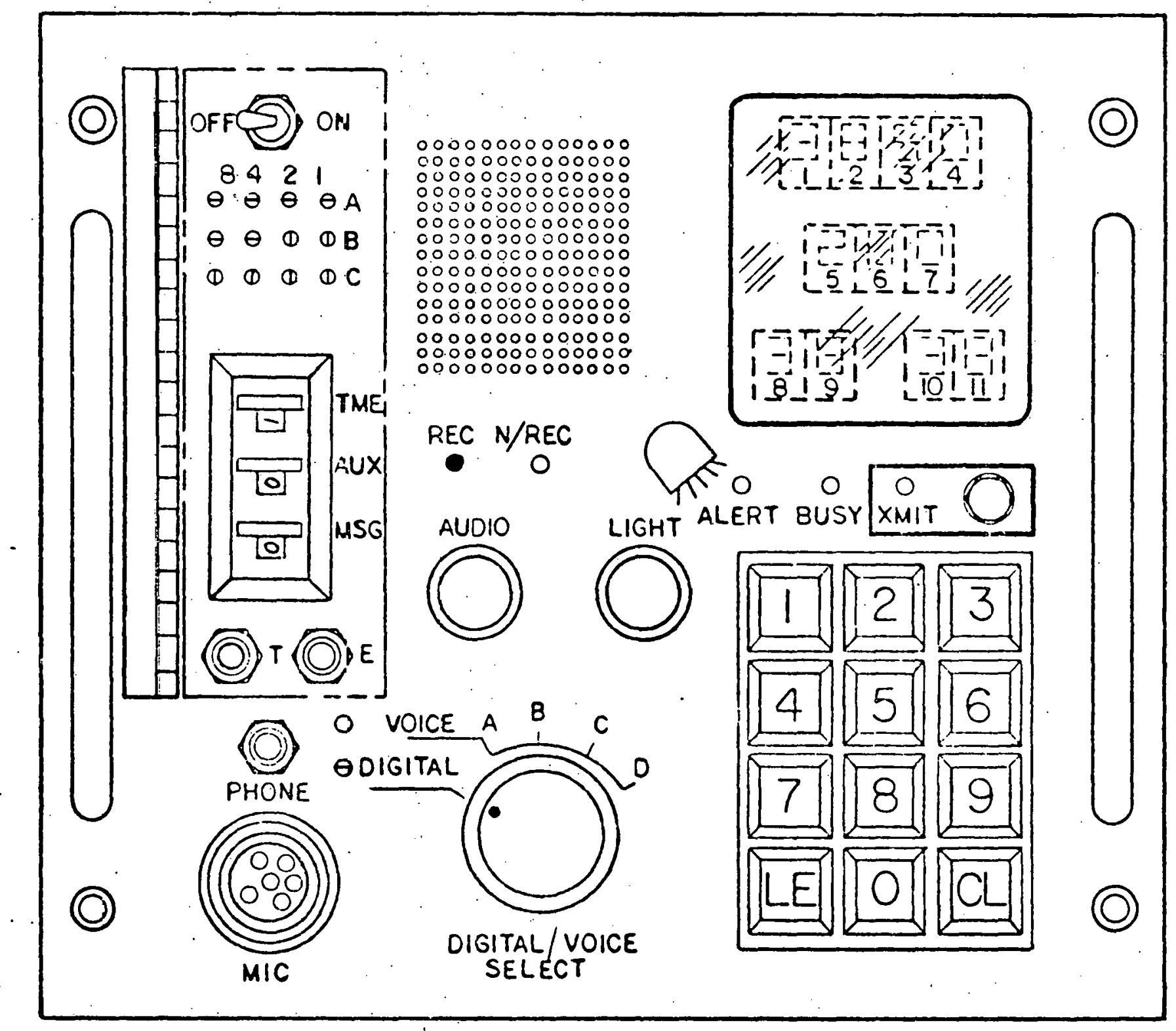

FIGURE 6 
VEHICLE TRANSMITTED MESSAGE - 100 BITS

\begin{tabular}{|l|l|l|}
\hline PREAMBLE (20) & DATA (64) & CRC (16) \\
\hline
\end{tabular}

BI-PHASE DIGITAL CODING

DATA RATE $=300$ BPS

FSK FREQUENCY $=1300 \& 2100 \mathrm{~Hz}$

FIGURE 7 


\section{VEHICLE MESSAGE SEQUENCE:}

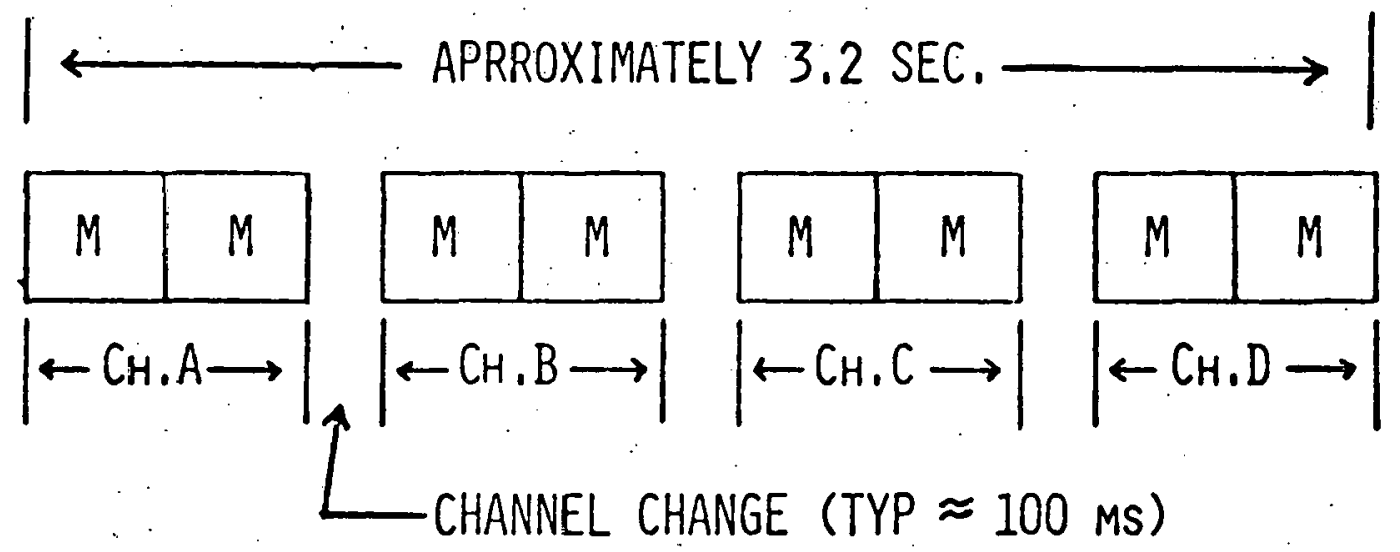

IF ACKNOWLEDGE NOT RECEIVED, REPEATED IN 30-40 SECONDS (5 ATTEMPTS MAXIMUM) 


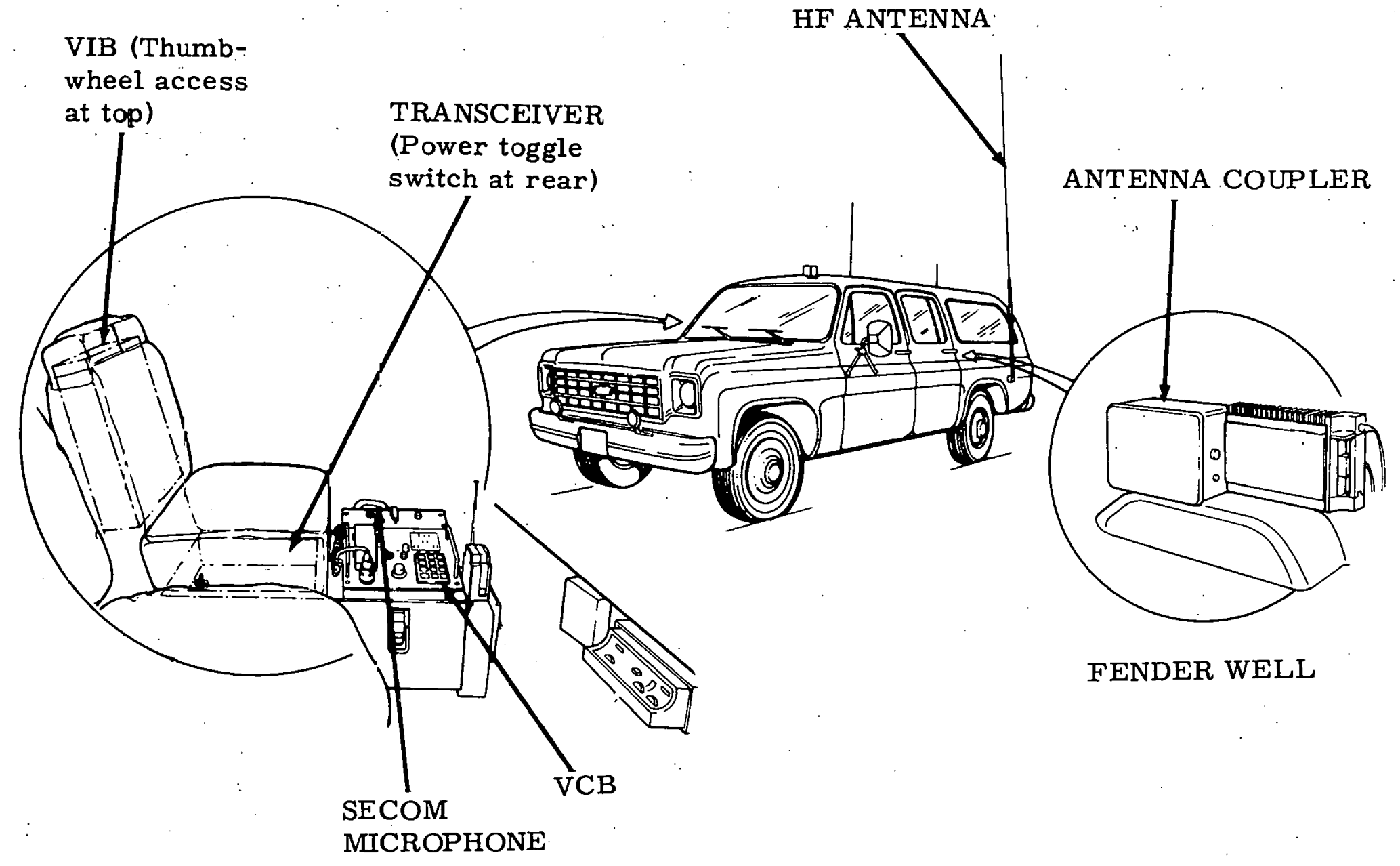

FIGURE 9 


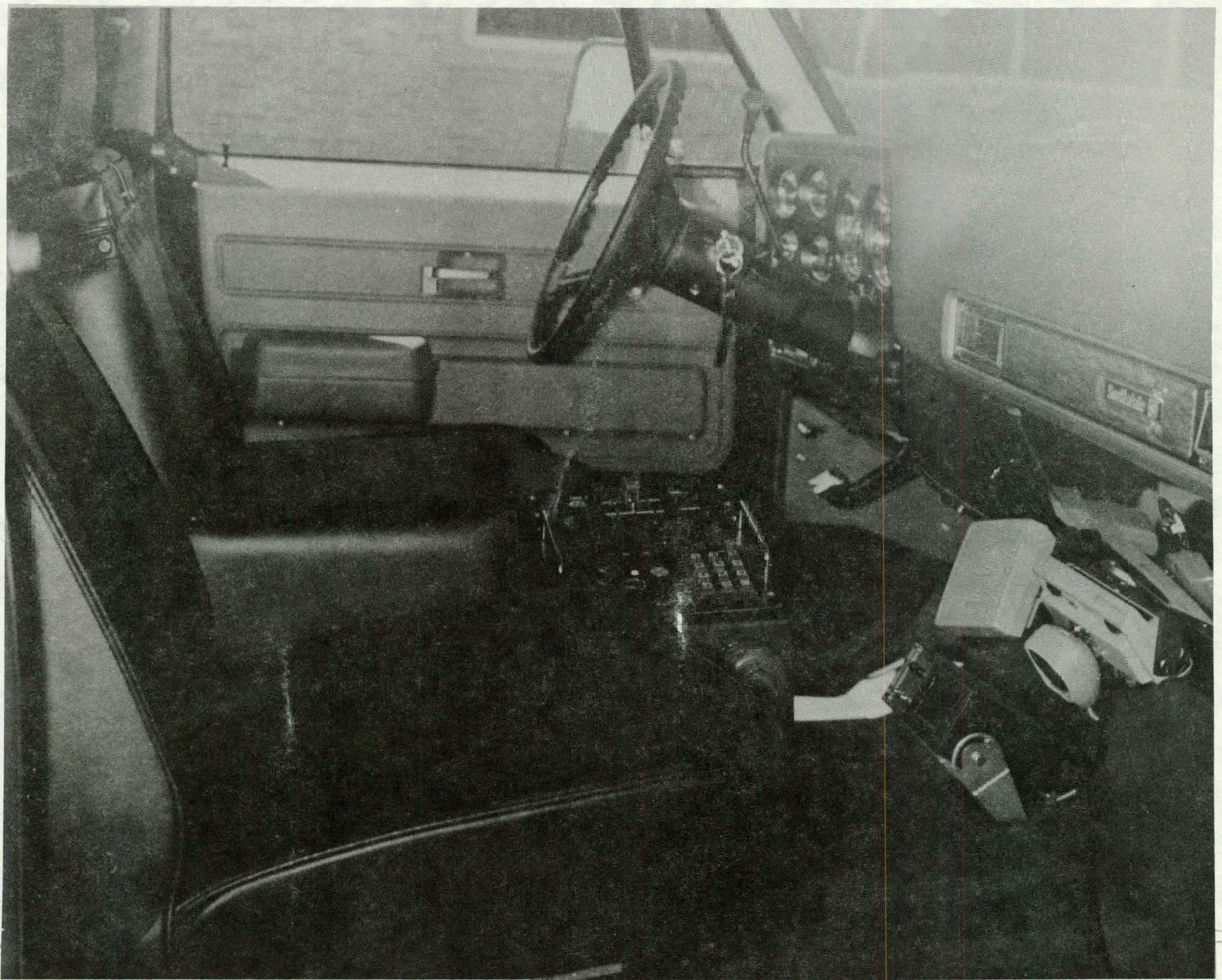

FIGURE 10 


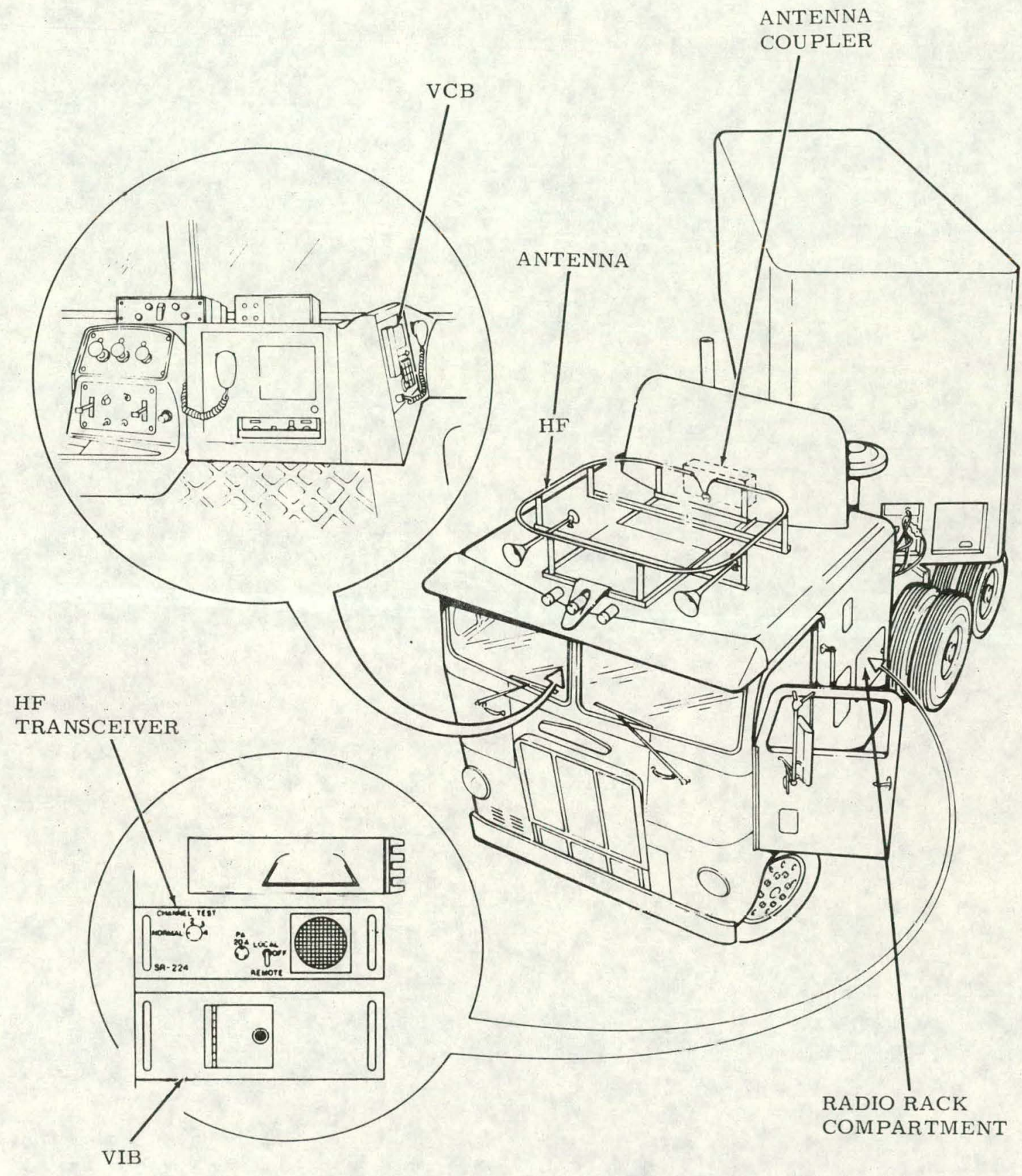

FIGURE 11 


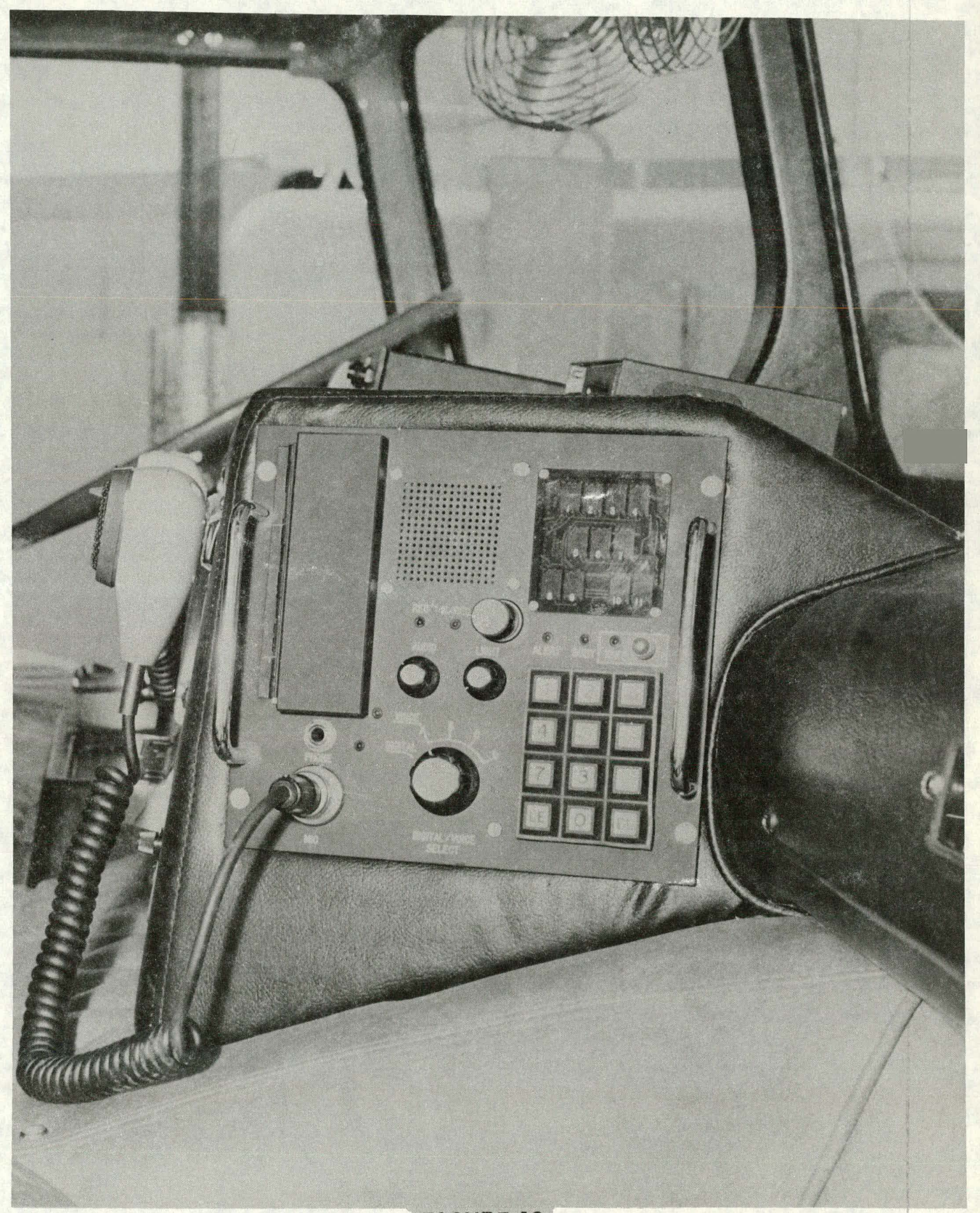

FIGURE 12 


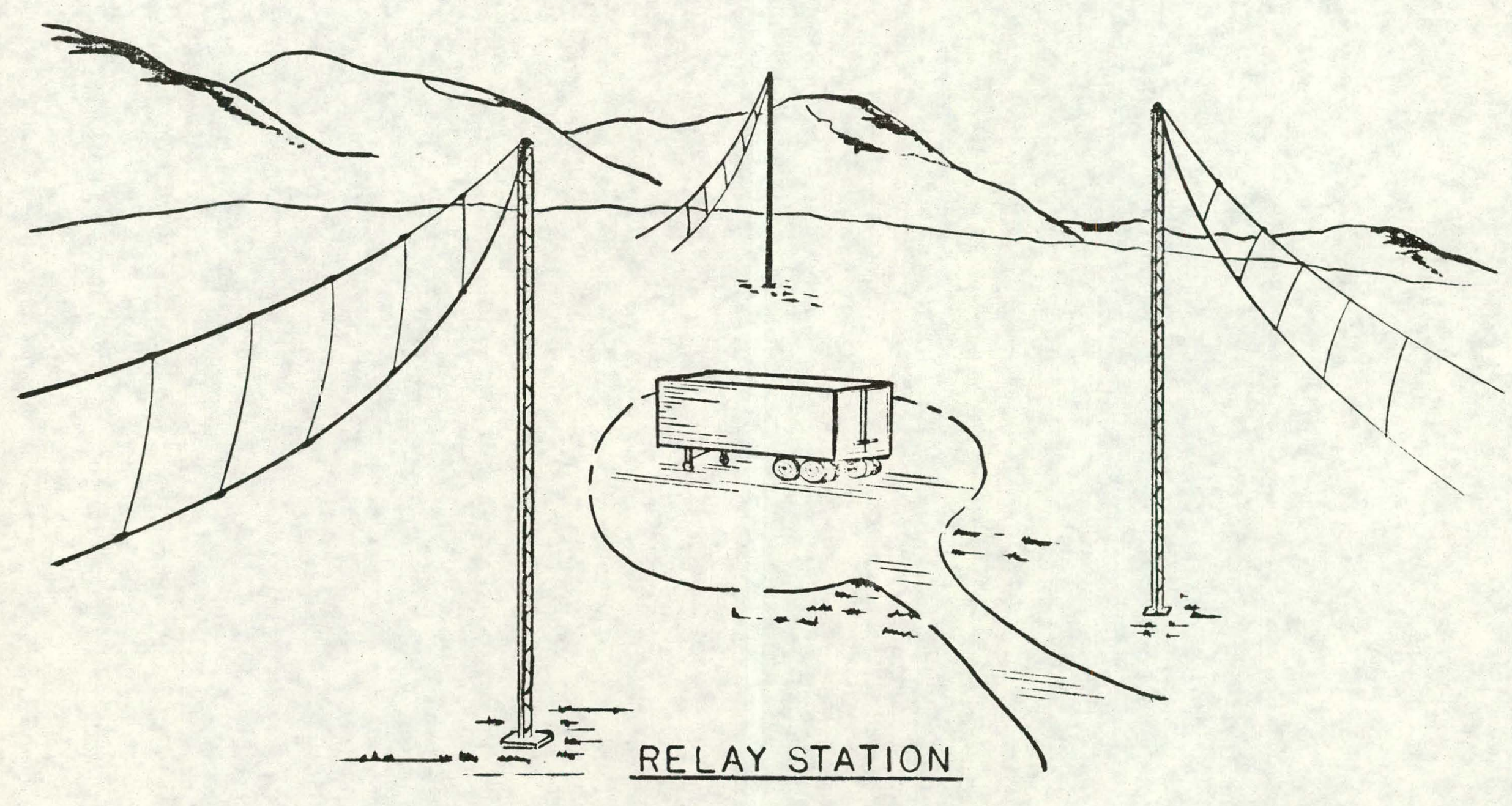

FIGURE 13 


\section{RELAY STATION PROCESSING}

- BIT-BY-BIT MAJORITY LOGIC OF ALL RECEIVED MESSAGES.

- ERROR DETECTING CODE CHECK OF MAJORITY MESSAGE,

- attach RECEIVEd MESSAge COUNT dATA tO MAJORItY MESSAge

- GENERATE NEW ERROR DETECTING CODE.

- TRANSMit MESSAgE THREE CONSECUTIVE TIMES AT 1200 BPS OVER PHONE LINE TO SCC.

FIGURE 14 


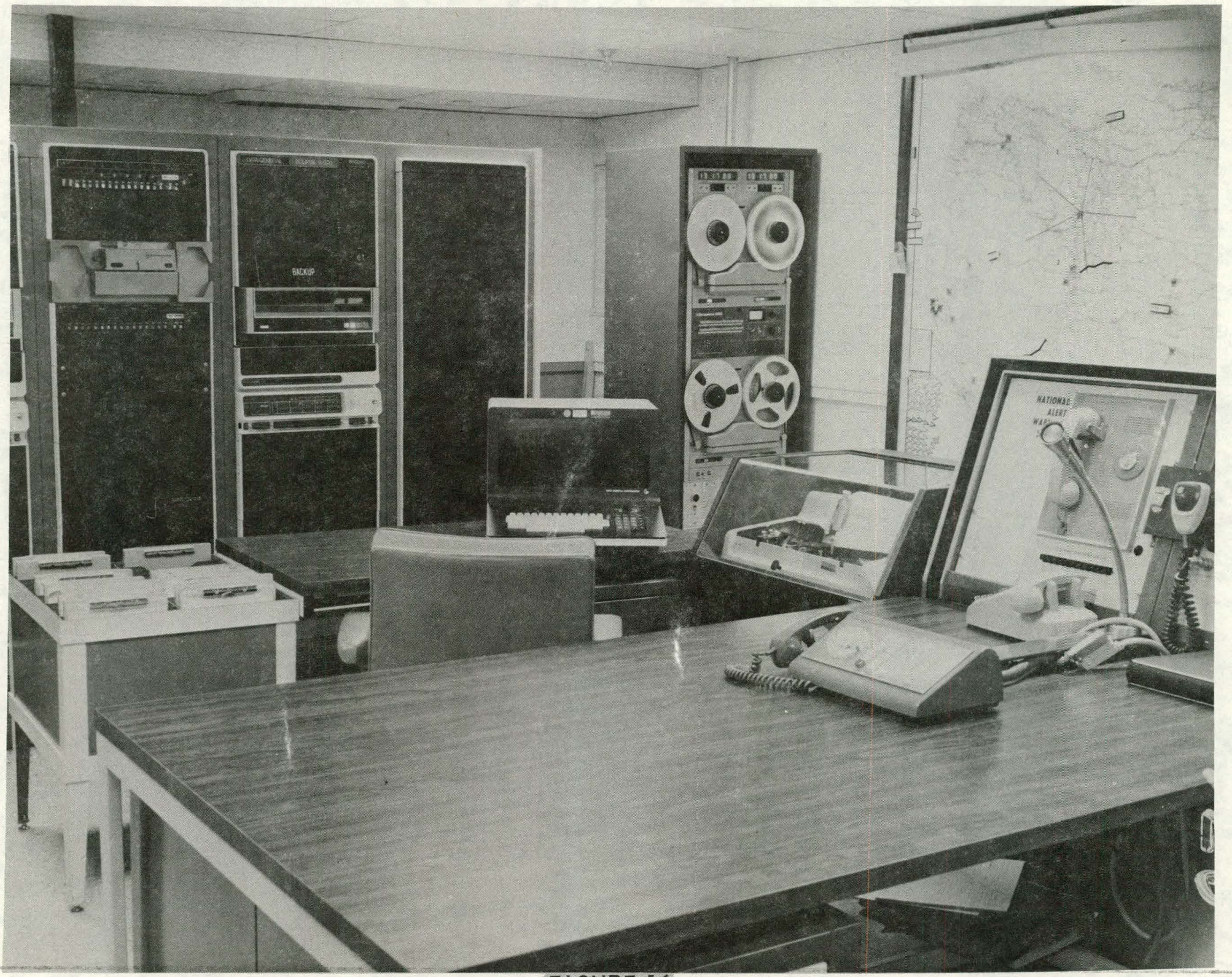

FIGURE 16 


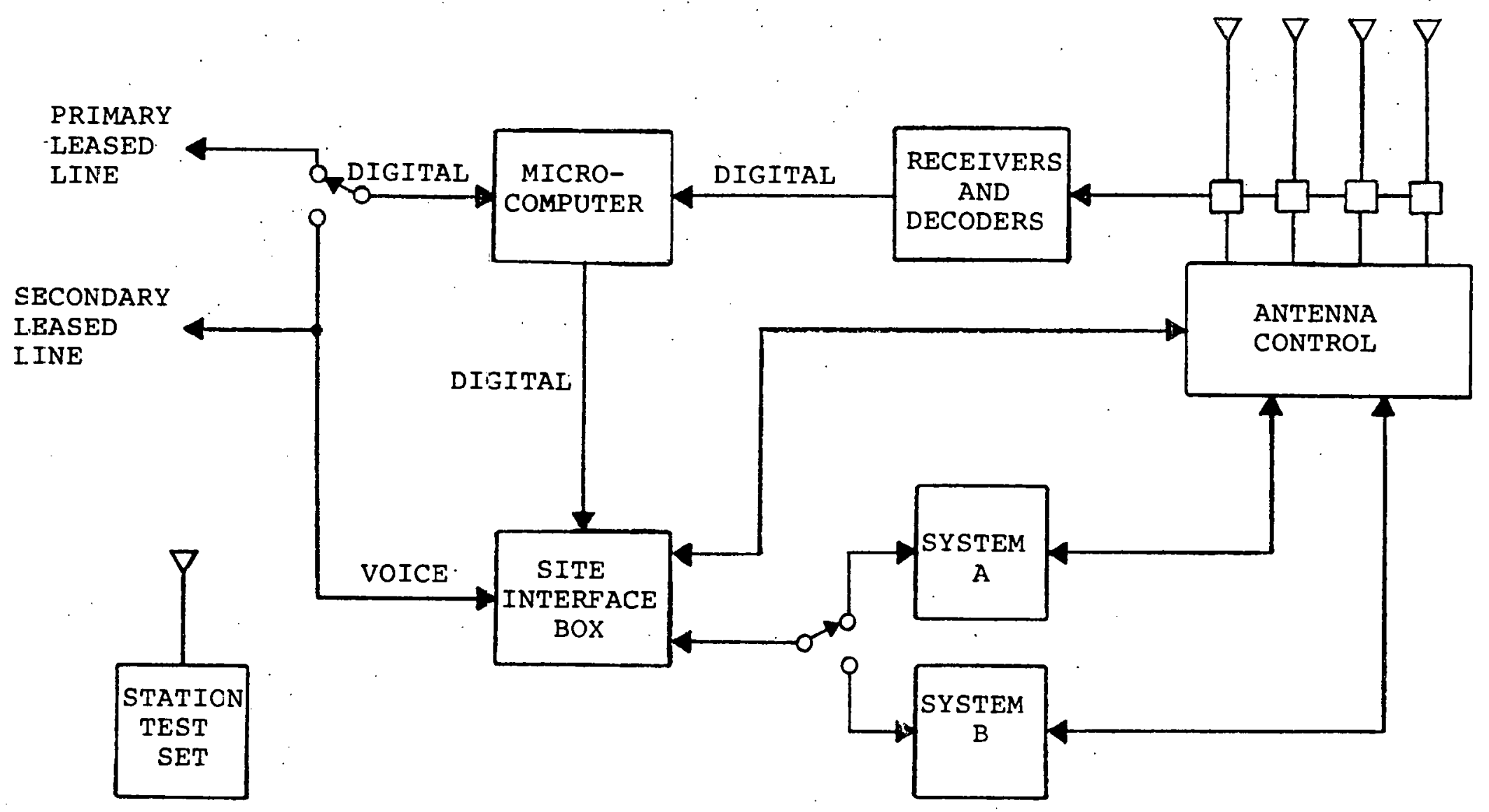

FIGURE 15

RELAY STATION BLOCK DIAGRAM 


\section{SECOM CONTROL CENTER PROCESSING}

- RECEIVE MESSAgES fROM. up to five Stations.

- PERform MAJORITY LOGIC AND CRC CODE CHECKS.

- DETERMine beSt StATION, ANTENNA AND CHANNEL FOR RESPONSE.

- GENERATE AiND tRANSMit AUTO-ACKNOWLEDGE THROUGH SELECTED RELAY STATIONS.

- SEND MESSAGES TO CRT, PRINTER AND DISK FILE. 


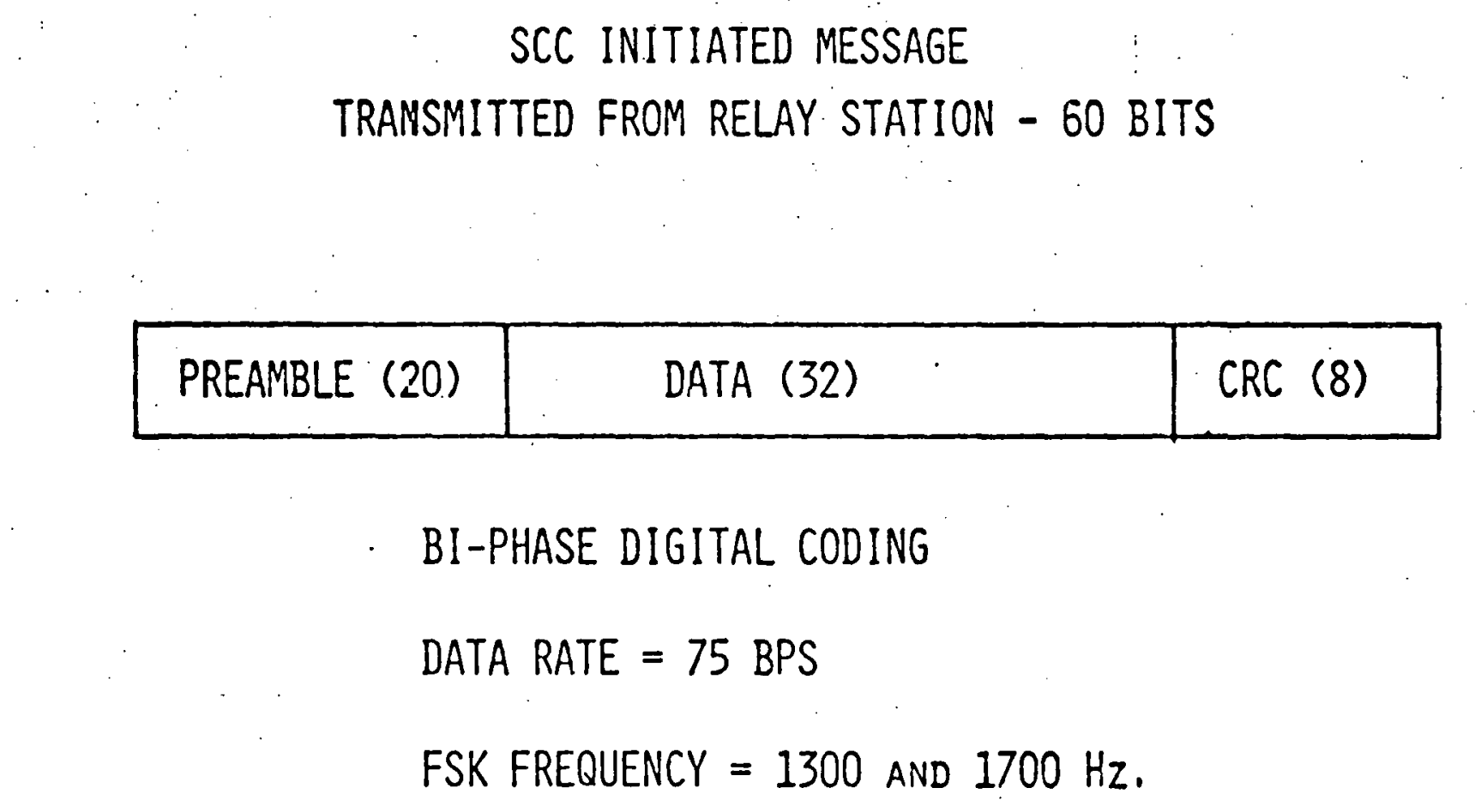

TRANSMITTED FOUR CONSECUTIVE TIMES ON COMPUTER-SELECTED BEST STATION. ANTENNA AND CHANNEL

FIGURE 18 
TYPICAL OPERATOR DISPLAY

VEH TIME CKPT AUTH RECV AUX XMIT $12: 19$

$\begin{array}{lll}101 & 11: 26 & 2546 \\ 102 & 12: 01 & 3081\end{array}$

$121 \quad 12: 14 \quad 1141$

$122 \quad 11: 19 \quad 2419$

$123 \quad 10: 45 \quad 3734$

$124 \quad 11: 37 \quad 1729$

$13412: 131111$

$135 \quad 11: 57 \quad 2027$

$145 \quad 12: 00 \quad 1732$

$146 \quad 11: 50 \quad 1227$

$147 \quad 10: 01 \quad 3566$

$161 \quad 9: 50 \quad 1394$

$162 \quad 11: 59 \quad 3591$

$163 \quad 9: 55 \quad 1406$

$235 \quad 12: 12 \quad 1206$
464. $3000 \quad 0$ $010 \quad 3 \quad 000 \quad 0$ $\begin{array}{llll}368 & 3 & 000 & 0\end{array}$ $\begin{array}{llll}816 & 3 & 000 & 0\end{array}$ $\begin{array}{llll}581 & 3 & 000 & 0\end{array}$ $391 \quad 3 \quad 000 \quad 0$ $\begin{array}{llll}111 & 51 & 000 & 0\end{array}$ $\begin{array}{llll}642 & 3 & 000 & 0\end{array}$ $\begin{array}{llll}305 & 38 & 000 & 4\end{array}$ $\begin{array}{llll}773 & 3 & 000 & 0\end{array}$ $\begin{array}{llll}910 & 3 & 000 & 0\end{array}$ $\begin{array}{llll}179 & 3 & 000 & 0\end{array}$ $\begin{array}{llll}256 & 37 & 000 & 4\end{array}$ $\begin{array}{llll}604 & 3 & 000 & 0\end{array}$
VEH TIME CKPT AUTH RECV AUX XMIT

$\begin{array}{lllllll}236 & 12: 05 & 3014 & 158 & 3 & 000 & 0\end{array}$ $\begin{array}{rrrrrrr}311 & 12: 10 & 1111 & 111 & 51 & 000 & 0\end{array}$

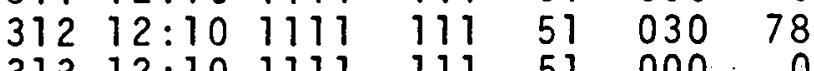

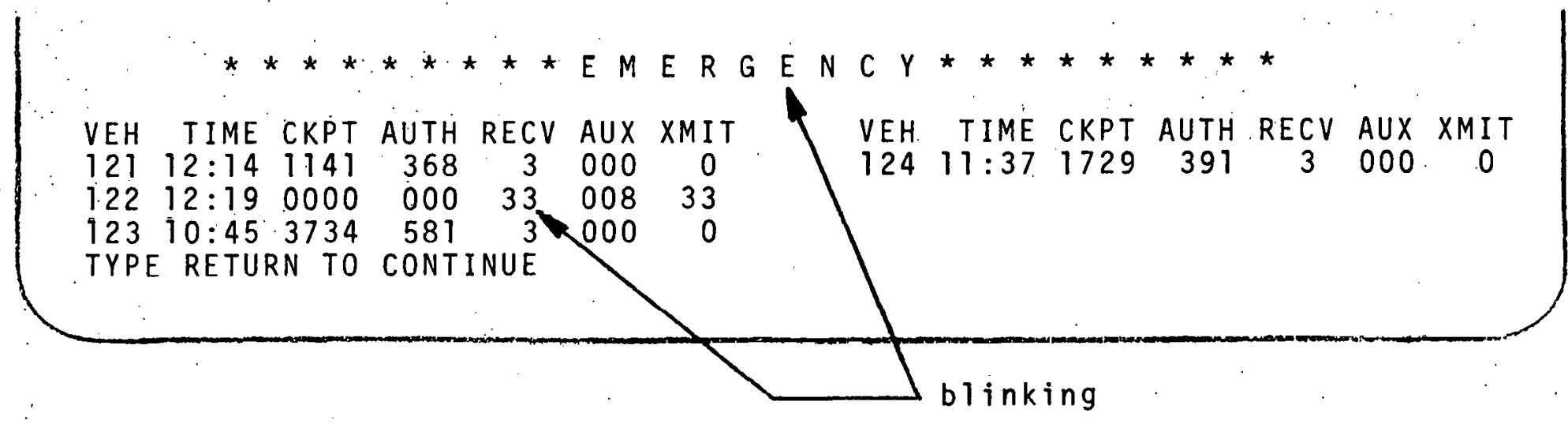




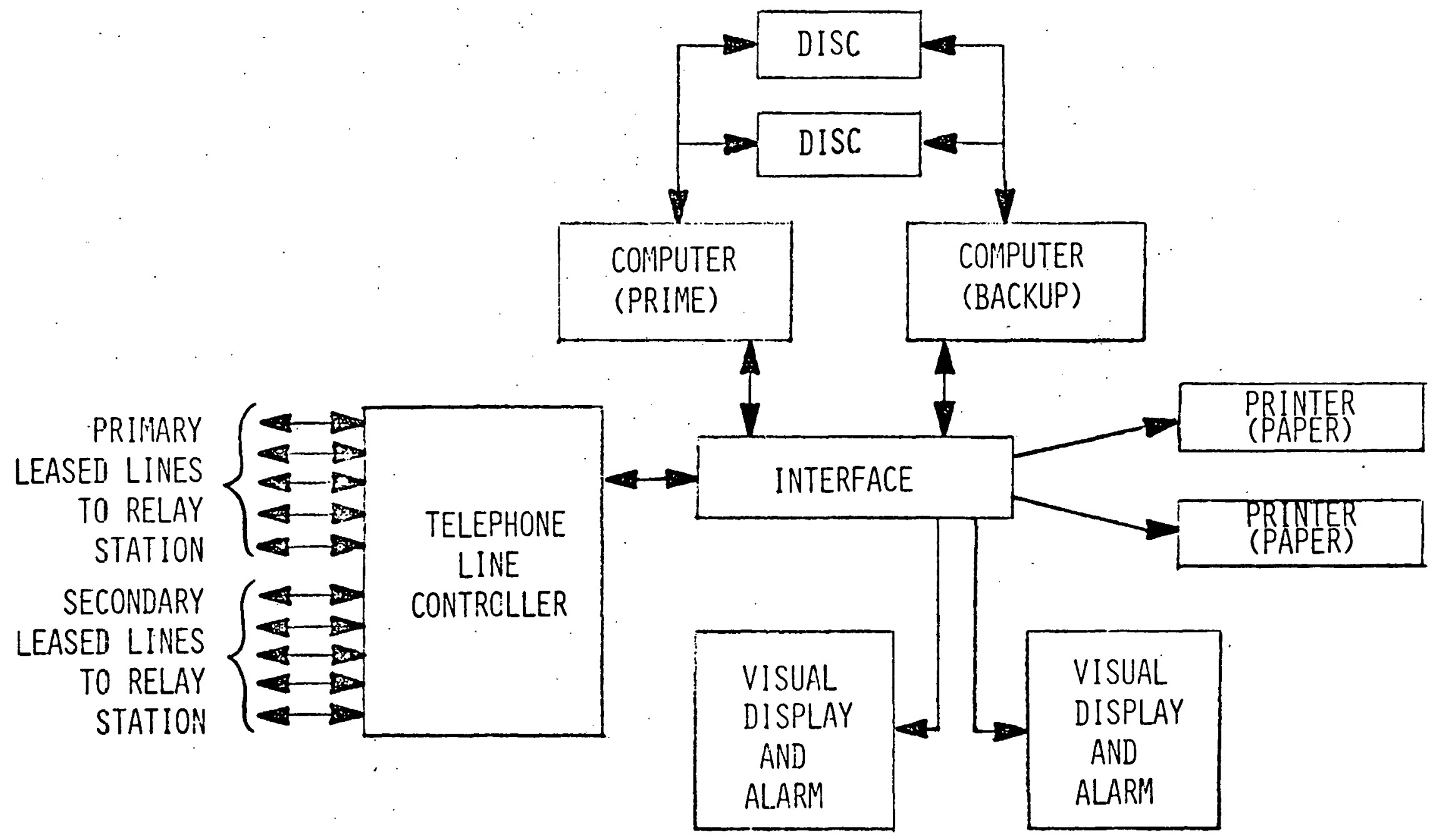

CENTRAL CONTROL STATION

FIGURE 20 


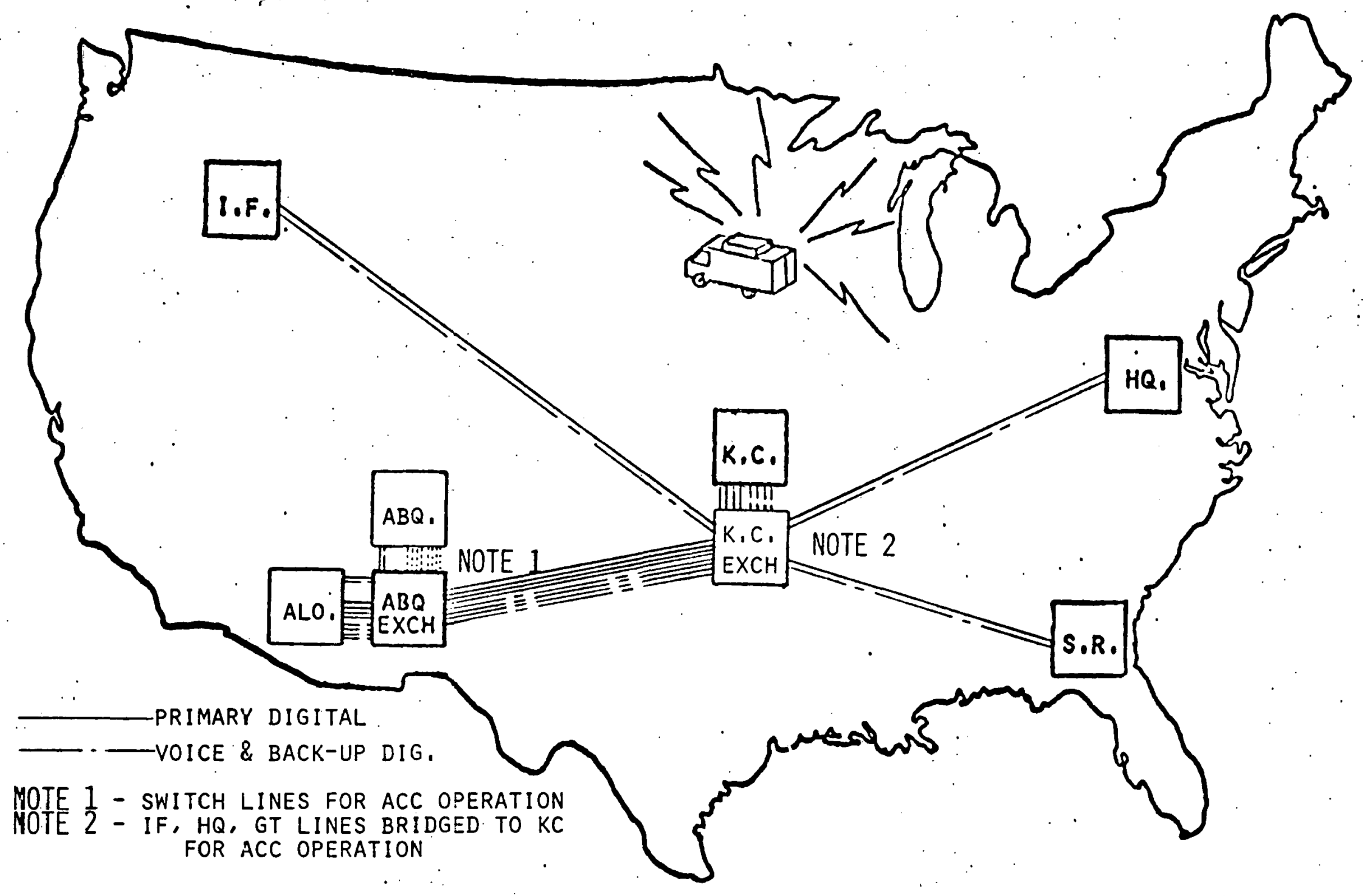

SECOM II LEASED LINE NETWORK

FIGURE 21 


\section{DIGITAL COMMUNICATIONS SYSTEM}

\section{CHARACTERISTICS}

1. TWO-WAY DIGITAL /EMERGENCY VOICE

2. AUTOMATIC, REDUNDANT TRANSMISSION ON 4 HF CHANNELS: 3-12 MHZ

3. RAPID TRANSMISSION (4 SEC), AUTOMATIC ACKNOWLEDGEMENT

4. AUTOMATED CENTRAL CONTROL STATION

IMPROVEMENTS OVER ALL-VOICE SYSTEM

1. INCREASED TRAFFIC HANDLING

2. INCREASED MESSAGE SECURITY

3. IMPROVED PROBABILITY OF SUCCESSFUL COMMUNICATIONS

4. REDUCED PERSONNEL: UNMANNED, AUTOMATED RELAYS

5. AUTOMATED CENTRAL RECORD-KEEPING / RESPONSE

6. ABILITY TO INCORPORATE LICENSEE-OWNED SHIPMENTS

7. IMPROVED PERSONNEL OPERATING CONDITIONS

8. KEY TO OPERATOR-INDEPENDENT SYSTEM 